\title{
II. HEMORRHAGIC DISEASE. ANTITHROMBIN AND PROTHROMBIN FACTORS *
}

\author{
G. H. WHIPPLE, M.D. \\ BALTIMORE, MD.
}

In a previous communication dealing with various types of hemorrhagic disease (Whipple ${ }^{1}$ ), we suggested that one factor, namely, antithrombin, might be of importance in various types of bleeding. The other elements of blood coagulation were taken up and some of the work on normal blood coagulation was reviewed. Because it is of great importance to have clearly in mind the mechanism of normal blood coagulation, it may be well to detail briefly Howell's ${ }^{2}$ theory, as it seems to meet all the known requirements in the most satisfactory manner.

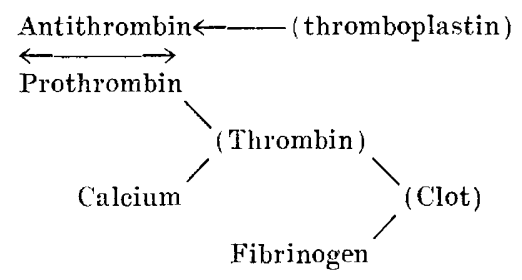

This shows in a schematic way the manner of blood coagulation. Howell believes that a small amount of antithrombin is present in the normal plasma and is sufficient to bind the prothrombin and render it inactive. Thromboplastin is set free by cell injury (blood-cells, platelets, tissues, cells, etc.), and neutralizes the antithrombin. This frees the prothrombin, which at once combines with calcium to form thrombin. The free thrombin coagulates the fibrinogen, giving the normal clot.

It is at once evident that this balance of antithrombin and prothrombin must be extremely delicate and capable of rapid adjustment. When the antithrombin accumulates in excess, the appearance of purpura and bleeding is to be expected, but if the antithrombin drops to a low level, spontaneous thrombosis might occur.

It is not surprising then that this very point seems to be the one about which most of the interesting cases of hemorrhagic disease may be grouped.

* From the Hunterian Laboratory of Experimental Pathology, Johns Hopkins Medical School.

* Submitted for publication Oct. 17, 1913.

1. Whipple, G. H.: The Archives Int. Med., 1912, ix, 365.

2. Howell: Am. Jour. Physiol., 1910, xxvi, 453. 


\section{METHOD}

Blood was obtained in all cases before death by means of a needle in a vein. The blood was aspirated into a solution of sodium oxalate ( 1 per cent.), the dilution being nine parts blood to one of oxalate. The blood from autopsy cases was usually obtained directly from the heart by means of a trocar and drawn into a bottle containing oxalate. Clear plasma was obtained by centrifugalization. In all experiments the calcium was supplied in the form of 1 per cent. calcium chlorid solution. The coagulation experiments were always done with the fresh blood plasma unless otherwise stated and the observation usually completed within two to six hours after the blood had been obtained. Control plasma from normal men, cats or dogs was always used fresh. Spleen extract was used only when fresh and made up by grinding the spleen with sand to a thin paste, adding sufficient salt solution and filtering through paper.

\section{JCTERUS, LIVER DISEASE, BLEEDING}

Cass 1.-Carroll. White male, aged 75. Admission July 11, 1912. Death July 20, 1912. Complaint, jaundice.

Family history negative. Past history negative, except strong alcoholic history up to 17 years ago.

P. I. Began April 19, 1912, with sudden appearance of jaundice which has been continuous ever since. On admission, skin was of a deep bronze color. The liver was definitely enlarged. There were marked hemorrhoids. Urine rich in bile. The general clinical picture suggested the diagnosis of cancer of the head of the pancreas.

July 12. White blood cells 12,100 . Hb. 82 per cent. Stools contained no blood and were of acholic type. No evidence of bleeding.

July 13. No evidence of bleeding. Intense icterus. Blood drawn directly into oxalate from arm vein. (Table 1.)

Table 1.-Case 1. Coagulation Time of Blood in Jaundice

\begin{tabular}{c|c|c|c}
\hline $\begin{array}{c}\text { Plasma C } \\
\text { c.c }\end{array}$ & $\begin{array}{c}\text { Plasma } \mathrm{H} \\
\text { c.c }\end{array}$ & $\begin{array}{c}\text { Calcium Solution } \\
\text { Drops }\end{array}$ & $\begin{array}{c}\text { Coagulation Time } \\
\text { Minutes }\end{array}$ \\
\hline 1 & $\ldots$ & 3 & 8 \\
1 & $\ldots$ & 4 & 8 \\
1 & $\cdots$ & 2 & No clot \\
$\ldots$ & 1 & 5 & 5 \\
\hline
\end{tabular}

Plasma $\mathrm{H}$ is from a normal man. The slight delay of coagulation (Carroll) comes nearly within normal limits but may in riew of later developments indicate a slight excess of antithrombin.

July 17. Red blood-cells 3,500,000, Hb. 70 per cent. W. B. C. 12,400. Bleeding was first noticed. There was oozing from the mouth, and blood-stained feces. Patient was in a low delirium.

July 18. Patient bleeding from mouth and there is some blood-stained vomitus. Blood is present in the stools and patient appears sick and is losing ground rapidly.

2:30 p. m. Blood drawn directly from vein into oxalate. This plasma showed an excess of antithrombin. (Table 2.) 
TABLE 2.-Case 1. Second Experiment

\begin{tabular}{|c|c|c|c|c|}
\hline \multirow{2}{*}{$\begin{array}{c}\text { Plasma } C \\
\text { c.c. }\end{array}$} & \multirow{2}{*}{$\begin{array}{c}\text { Plasma } D \\
\text { c.c. }\end{array}$} & \multirow{2}{*}{$\begin{array}{c}\text { Calcium Solution } \\
\text { Drops }\end{array}$} & \multicolumn{2}{|c|}{$\begin{array}{c}\text { Coagulation Time } \\
\text { Minutes }\end{array}$} \\
\hline & & & Start & End \\
\hline 1 & .. & 3 & 14 & $40^{*}$ \\
\hline 1 & . & 5 & 17 & $60^{*}$ \\
\hline & 1 & 4 & 3 & 3 \\
\hline 2 & 1 & 15 & $31 / 2$ & 8 \\
\hline & 1 & 4 & 3 & 4 \\
\hline 3 & $\mathrm{I}$ & 13 & $41 / 2$ & 11 \\
\hline 1 & $\ldots$ & 2 & 26 & .. \\
\hline 1 & $\ldots$ & 1 & 26 & $\cdots$ \\
\hline 1 & 1 & 7 & $51 / 2$ & $8-11$ * \\
\hline
\end{tabular}

* Clots wiped out often and subsequent clots formed slowly up to the final time. Plasma D obtained from a normal dog.

July 19, 9 a. $\mathbf{m}$. The plasmas used on previous day were kept on ice. Fresh spleen extract made as usual. (Table 3.)

TABLE 3.-Case 1. Thind Experiment

\begin{tabular}{|c|c|c|c|c|c|}
\hline \multirow{2}{*}{$\begin{array}{c}\text { Plasma C, } \\
\text { c.c. }\end{array}$} & \multirow{2}{*}{$\begin{array}{c}\text { Plasma D, } \\
\text { c.c. }\end{array}$} & \multirow{2}{*}{$\begin{array}{l}\text { Spleen } \\
\text { Extract } \\
\text { Drops }\end{array}$} & \multirow{2}{*}{$\begin{array}{l}\text { Calcium } \\
\text { Drops }\end{array}$} & \multicolumn{2}{|c|}{$\begin{array}{c}\text { Coagulation Time, } \\
\text { Minutes }\end{array}$} \\
\hline & & & & Start & End \\
\hline $\begin{array}{l}1 \\
1 \\
1 \\
\cdots\end{array}$ & $\begin{array}{l}\cdots \\
\cdots \\
1\end{array}$ & $\begin{array}{r}\dddot{4} \\
5 \\
6\end{array}$ & $\begin{array}{l}3 \\
3 \\
3 \\
5\end{array}$ & $\begin{array}{l}35 \\
31 / 2 \\
31 / 2 \\
1\end{array}$ & $\begin{array}{l}\ddot{8}-12 \\
6 \\
\cdots\end{array}$ \\
\hline
\end{tabular}

Fresh spleen extract is rich in thromboplastin which can neutralize antithrombin with rapidity. It overcomes the slight amount of antithrombin in normal plasma and clots it in one minute, while the coagulation time of the antithrombin plasma is lowered to one-tenth its control. (Table 3, Case 1.)

July 20, 1 a. $m$. Death took place. Patient had been in a semistupor for the previous twelve hours. Temperature had been constantly subnormal.

1:20 a. m. Blood obtained directly from auricle and drawn into oxalate. The tests given below were performed immediately. Analysis shows the excess of antithrombin to have disappeared in great part, while the prothrombin has greatly diminished in amount. (Table 4.)

1. Blood drawn into clean bottle (no oxalate) began to clot slightly at edges after one and one-half hours; after twelve hours a flabby clot had formed all through the blood. After thirty-six hours in the ice box a tough clot had formed with retraction and escape of serum. There was no evidence of clot autolysis after three days.

2. Plasma $\mathrm{C}, 1$ blood drawn into a clean bottle (no oxalate) and a few minutes later centrifugalized. Plasma a dirty orange yellow, slightly opalescent and rich in bile pigments. This plasma kept in a beaker free from blood cells showed a few filmy clots in one and one-haif hours and thin clots on the wall of the 
vessel after twelve hours, the center being free from clots. After twenty-six hours coagulation was not complete. At the end of three days a firm clot was formed.

3. Plasma $\mathrm{C}^{2}$ blood (Carroll) drawn into oxalate, centrifuged and preserved as usual - no clots formed.

4. Plasma D, oxalate plasma from a normal dog.

5. Spleen extract from the same dog, about twelve hours postmortem.

TABLE 4.-Case 1. Fourtil Experiment

\begin{tabular}{|c|c|c|c|c|c|c|}
\hline \multirow{2}{*}{$\begin{array}{c}\text { Plasma C, } \\
\text { No Oxalate } \\
\text { c.c. }\end{array}$} & \multirow{2}{*}{$\begin{array}{c}\text { Plasma } \mathrm{C}^{2}, \\
\text { Oxalated, } \\
\text { c.c. }\end{array}$} & \multirow{2}{*}{$\begin{array}{c}\text { Plasma D, } \\
\text { Oxalated, } \\
\text { c.c. }\end{array}$} & \multirow{2}{*}{$\begin{array}{l}\text { Spleen } \\
\text { Extract } \\
\text { Drops }\end{array}$} & \multirow{2}{*}{$\begin{array}{l}\text { Calcium } \\
\text { Drops }\end{array}$} & \multicolumn{2}{|c|}{$\begin{array}{c}\text { Coagulation Time, } \\
\text { Minutes }\end{array}$} \\
\hline & & & & & Start & End \\
\hline 1 & $\cdots \cdots$ & $\ldots \ldots$ & $\cdots \cdots$ & & $30-60$ & \\
\hline 1 & $\ldots \ldots$ & $\ldots \ldots$ & $\ldots \ldots$ & 2 & 40 & \\
\hline 1 & $\ldots \ldots$ & $\ldots \ldots$ & 5 & $\ldots \ldots$ & 35 & 50 \\
\hline 1 & $\ldots \ldots$ & $\ldots \ldots$ & 10 & $\ldots \ldots$ & 35 & 60 \\
\hline 1 & $\ldots \ldots$ & $* 1$ & $\ldots \ldots$ & $\ldots \ldots$ & 12 & $30+$ \\
\hline$\ldots \ldots$ & $\ldots \ldots$ & 1 & 7 & 5 & $1 / 2$ & $1 / 2$ \\
\hline 1 & $\ldots \ldots$ & 1 & 7 & 5 & $1 / 2$ & $1 / 2$ \\
\hline 1 & $\ldots \ldots$ & $\ldots \ldots$ & 5 & 2 & 14 & 23 \\
\hline 2 & $\ldots \ldots$ & 1 & $\ldots \ldots$ & 5 & 4 & 6 \\
\hline$\ldots \ldots$ & 1 & $\ldots \ldots$ & $\ldots \ldots$ & 5 & 50 & $\ldots \ldots$ \\
\hline$\ldots \ldots$ & 1 & $* 1$ & $\ldots \ldots$ & 3 & 6 & \\
\hline
\end{tabular}

* Dog serum, which was twelve hours postmortem.

From an analysis of Table 4 we may conclude that the excess of antithrombin has completely disappeared from this blood, leaving only a small amount which may be within normal limits. The prothrombin has been greatly diminished, but has fallen not quite to zero, as the blood will clot in hours or days. This blood does not inhibit normal plasma coagulation. Spleen extract causes some acceleration of coagulation as does calcium, but the great deviation from normal consists in a great drop of the prothrombin content.

The spleen from this case was tested for its thromboplastin and found to contain very little of this element. Unfortunately, spleen extracts vary greatly in their thromboplastic activity, but it is possible that this organ had been depleted of its thromboplastin, which had been used in the neutralization of the blood antithrombin.

Necropsy No. 3754.-Anatomical diagnosis: Carcinoma of the head of the pancreas with complete occlusion of the common bile and pancreatic ducts; extreme icterus; dilatation of bile passages and gall bladder; cirrhosis and central necrosis of liver; dilatation of pancreatic ducts with chronic pancreatitis; metastases to the nearby lymph-nodes and liver; purpura, submucous, subserous and disseminated echymoses; gastric and intestinal hemorrhage; pulmonary ecchymoses, hemorrhage and edema; absence of blood clots in vascular system; general arteriosclerosis; emphysema of lungs; chronic adhesive peritonitis and pleuritis; caseous bronchial lymph-nodes: hrpertrophy of prostate; slight chronic nephritis. 
The body is that of a large white male, $161 \mathrm{~cm}$. long. Rigor mortis is pres. ent. The skin everywhere has a deep icteric hue. The pupils are equal. There are indefinite purpuric splotches about the eye, at the bend of the elbow (blood culture) on the forearm and groin and over the flanks. Liver mortis is conspicuous. On incision the subcutaneous fat is pretty well preserved and of a deep yellow color. Scattered throughout the fat, over the abdomen particularly, are little hemorrhages. The abdomen on incision contains highly colored, orangeyellow, slightly turbid fluid (500 c.c. in amount). The small intestine is moderately dilated with gas and presents a mottled purplish appearance apparently due to blood either in the mucosa or lumen. The liver appears about 5 or $6 \mathrm{~cm}$. below the costal margin and is deep green in color and presents several grayish nodules apparently a new growth. The gall-bladder is huge and slightly thickened, projecting just to the edge of the liver.

Thorax: The lungs are very voluminous, cushiony and cover over the heart. There are purplish flecks and splotehes in the fat over the pericardial sac, the larger ones measuring $1 \mathrm{~cm}$. The pericardial cavity contains a little bile stained, bloody fluid. The cavities of the heart contain no clots, and fluid blood runs out on section. The heart weighs $380 \mathrm{gm}$. Negative except for ecchymoses.

Spleen is large and soft, weighs $200 \mathrm{gm}$., measures $131 / 2 \times 8 \times 4 \mathrm{~cm}$. The capsule is irregular and roughened, specked with tiny ecchymoses and opaque yellow areas of thickening. There are extensive areas of thickening of the capsule near the hilum. On section the trabeculae are conspicuous. The blood-vessels stand open. The pulp scrapes off easily on the knife and is deep red, soft and velvety. The Malpighian bodies are very inconspicuous, $1 / 2 \mathrm{~mm}$. in size.

The duodenum is intimately associated with the hard mass which appears to occupy the region of the head of the pancreas. There are extensive areas of purpura in this region. The lesser peritoneal cavity is partially obliterated by adhesions binding the firm nodular pancreas to the region of the pylorus, gastric and hepatic omentum, as well as the posterior wall of the stomach. On dissecting out the common duct it is found to be enlarged and thickened forming a tube about $3 \frac{1}{2} \mathrm{~cm}$. in diameter, just outside of the wall of the duodenum. The enlarged gall-bladder measures $6 \frac{1}{2} \mathrm{~cm}$. in diameter and $14 \mathrm{~cm}$. in length. It is quite tense as is the common duct and distended. The cystic duct where it opens into the common duct measures about $1 \mathrm{~cm}$. in diameter. The gall-bladder contains inky, black, slimy, stringy material and no calculi.

The stomach contains slimy fluid material. Its mucosa has undergone some post-mortem digestion. Ecchymoses, however, are numerous and easily made out. The orifice of the bile papilla is quite conspicuous, nodular and hard. There are two purplish projections about this papilla, one about the site of the opening of the lesser pancreatic duct. The head of the pancreas is of almost stony hardness and the growth seems to form a part of the wall which occupies the position of the bile duct. Section through the body of the pancreas shows a greatly dilated duct measuring 8 or $9 \mathrm{~mm}$. in diameter. In the distal third of the organ the parenchyma is gray, translucent, very hard and firm, evidently in a condition of extreme chronic pancreatities with atrophy. No evidence of new growth. It is embedded in a thick layer of retroperitoneal fat. About the middle part of the pancreas it seems as though some of the tissue is replaced by a new growth, the tissue being grayer and more granular than the pancreatic tissue. Section through the head of the pancreas and papilla shows a continuous growth of new tissue replacing all the normal parenchyma.

The liver weighs $2,150 \mathrm{gm}$., measures $26 \times 21 \times 9 \mathrm{~cm}$. The surface is rather irregular, due to the presence of gray nodules, some scarcely visible, other larger ones, 2 or more $\mathrm{cm}$. in diameter. The larger ones are, as a rule, associated with more or less hemorrhage. Many of them are umbilicated. They are firm to the touch. The liver tissue elsewhere has a slaty green color. On section the liver parenchyma presents a nutmeg architecture, deep green alternating with opaque gray areas, the latter being about the portal spaces. Tumor nodules of all 
sizes are scattered thickly over the section. The larger ones show central degeneration and necrosis. Some of the largest show softening associated with hemorrhage and digestion of the tissue, giving rise to cavity formation in the nodule.

Intestine: The jejunum shows a mucosa coated with currant-red, blood-stained mucus. Ecchymoses, however, are not numerous here, and this blood in great part eame from the stomach and duodenum. Low in the jejunum, however, are a few scattered ecchymoses 2 to $3 \mathrm{~mm}$. in diameter in the submucous tissue. The ileum is practically free from ecchymoses except occasional ones in the subnucosa. The large intestine shows a similar picture and contains a large amount of semifluid, blood-stained, fecal material. The other organs need not be described.

Microscopical Sections.-The lungs show hemorrhage into the alveoli with a good many polymorphonuclears, but no fibrin anywhere. In the spleen phagocytes containing old blood pigment are numerous. Marrow of femur shows little hyperplasia; phagocytes, as in the spleen, are numerous.

Kidney: Slight chronic nephritis. Glomeruli and tubules distended with granular, albuminous fluid. Some hemoglobin casts are found.

Liver: Moderate grade of portal cirrhosis with reaction of bile ducts and new formed strands of cells. The bile canaliculi are enormous and dilated with brown colloid material. The cancer nodules are associated with the portal structures. The central cells of many lobules show necrosis and there is no cellular reaction about these dead liver cells. In some areas pigmented phagocytes are crowded into the capillaries, perhaps the result of repair of preceding liver injuries.

There is abundant evidence of a progressive injury, inflammatory reaction and repair of the liver lobules. The large tumor nodules show extensive hemorrhage, but no fibrin in any section examined.

\section{ICTERUS AND HEMORRHAGIC DISEASE (CASE 1)}

There is much confusion about icterus and true hemorrhagic disease. The preceding case is a true example of jaundice and bleeding. It is familiar to all that a slightly delayed coagulation time is frequently associated with icterus, but such cases may be operated on with no danger and calcium will bring the coagulation time back to normal. We have suggested that this may be due to a binding of calcium by the bile pigments, a compound which is broken up with difficulty, and this renders the calcium slowly available for coagulation.

True hemorrhagic disease is rarely associated with obstructive jaundice, although the surgeons are fearful of this combination and often make a mistaken diagnosis. Calcium has no effect on this condition. For the past two years many cases of severe icterus have been examined, as a hemorrhagic tendency was suspected, but the case above is the only one of the series which showed true hemorrhagic disease.

It is of interest that we can follow the sequence of events in this case during the last week of life, while the patient developed this hemorrhagic tendency. 'The patient, in spite of intense icterus, of months' duration, showed no bleeding tendencies one week before death, and a blood with normal coagulation factors, except possibly a slight excess of antithrombin. Four days later true hemorrhagic symptoms appeared, which were due to an excess of antithrombin demonstrated in the blood. 
The blood obtained a few minutes after death showed only a slight amount of antithrombin-perhaps a normal amount-but a great drop in prothrombin, which caused great delay in blood coagulation.

This wide fluctuation of antithrombin and prothrombin is of much interest as they may be more or less interdependent. There is some evidence that antithrombin is produced in the liver. Under certain conditions and in certain diseases (melena neonatorum - -see below) this element may quite disappear from the blood, but study of such cases gives no clue to the origin of prothrombin.

Here we are dealing with a disease-complex in which surely the hepatic changes are conspicuous and probably most important from the standpoint of abnormality of blood coagulation - intense and longstanding icterus with great widening of the bile canaliculi and obvious embarrassment of these liver cells; cancer metastases with rapid invasion and destruction of parenchyma; liver cirrhosis of a moderate grade with new-formed cells and abortive bile-ducts; central liver necrosis of some days duration judging from the cell-picture, yet free from the usual invasion by wandering cells. Surely this is a liver laboring under difficulties and reacting to injury in an abnormal way. There is no good reason why such a liver could not produce an excess of antithrombin. Experiments have shown that various stimulants (peptone, thrombin, etc.), which produce an excess of antithrombin in the blood, will not do so if the liver is excluded; in other words, the antithrombin excess may be produced wholly within the liver. Moreover, there is evidence from certain experiments done in this laboratory that antithrombin is being constantly formed as it is used up and is furnished in great part by the liver.

When parenchyma cells are killed in the body, we may presuppose an escape of considerable amounts of thromboplastic substance. This must be neutralized by the antithrombin or by some other agents to prevent rapid intravascular clotting. Necrosis of liver cells presumably would free an excess of thromboplastin and necessitate its neutralization. In this case we have an excess of antithrombin which ranished during the time when liver necrosis developed. May we not conclude, then, that in this instance the antithrombin excess was removed or rendered inert by the thromboplastin which escaped from the necrotic liver cells?

The terminal drop in prothrombin tempts speculation, but it may be best to refrain. At least there is a possibility that the liver is concerned in the elaboration of this substance, prothrombin, which is so elusive. The prothrombin-antithrombin balance is so delicate and its constant maintenance so important to the organism that more than one organ may be concerned in the equation, as seems to be the case with fibrinogen (Goodpasture ${ }^{3}$ ).

3. Goodpasture: Am. Jour. Physiol., January, 1914. 


\section{TYPHOID (?) LIVER DISEASE (?) BLEEDING-RECOVERY}

Case 2,-Schwab. Medical No. 29,842. Thite male, aged 56. Admission Oct. 26, 1912. Recovery.

F. H., negative. P. H., typhoid fever at 19. Patient in bed ninety days. Various attacks of malaria for the previous fifteen years. History of moderate alcohol. Gonorrhea twenty-five years ago. Denies lues.

P. I. began October 12 with shaking chills and sweats. Since then patient has suffered from general weakness.

Oetober 26, red blood-cells 4,448,000. White blood-cells 12,600. Hb. 75 per cent.

October 28. Widal suggestive. Blood culture negative.

October 30. Temperature has been steadily elevated between 101 and $103 \mathrm{~F}$., giving a typhoid-like curve. Liver enlarged and smooth. Spleen not felt. White blood-cells 15,000. Blood smears negative. Wassermann negative.

November 2. Bleeding from the gums first noticed. Temperature falling gradually. Clinical diagnosis, typhoid fever.

November 3. Bleeding from gums quite marked. There are numerous subcutaneous hemorrhages. One measures $3 \mathrm{~cm}$. in diameter over the deltoid. Icterus noted in the subcutaneous tissue. Red blood-cells 3,512,000. W. B. C. 10,480. Hb. 65 per cent.

November 4 . Bleeding time estimated at thirty-four minutes and several hours later at eigheen minutes. Coagulation time seven minutes and forty seconds.

November 5. Stools contain blood. Bleeding from gums continuous. Jaundice quite evident. W. B. C. 9,000 . Liver palpable $6 \mathrm{~cm}$. below the costal margin. 'There are definite areas of purpura around ear pricks and abrasions in skin. Blood drawn directly into oxalate from arm veir (see Table 5). The analysis of this table shows a definite excess of antithrombin.

TABLE 5.-Case 2. Coagulation Time in Typhoid Fever

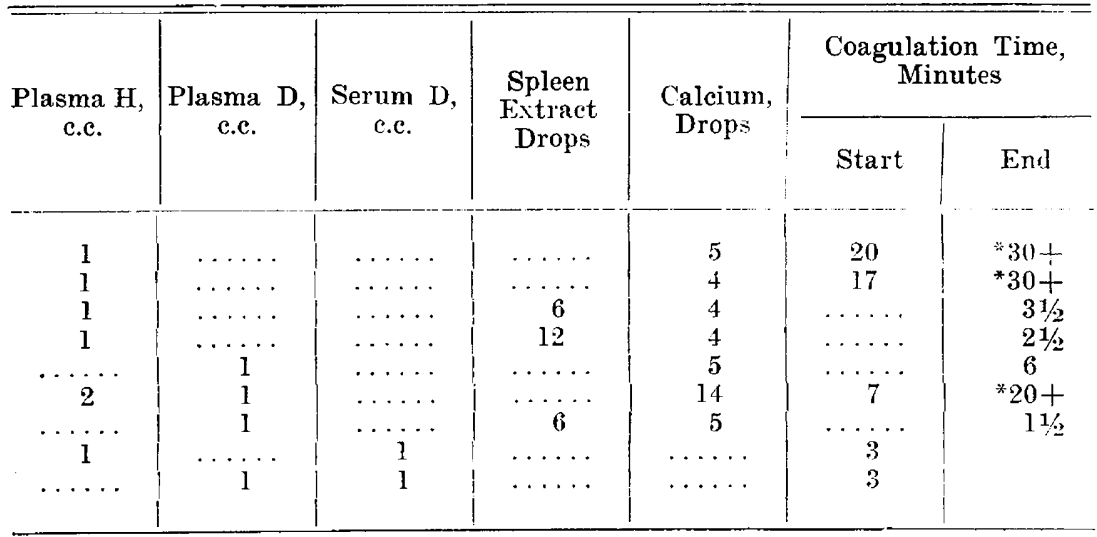

*Clots formed slowly, wiped out and continued to reform. Plasma D, Serum D and spleen extract (weak) all fresh and obtained from a normal dog.

November 6. Purpuric spots are numerous. The gums continue to on\%e blood. Widal with paratyphoid negative. Hb. 38 per cent.

November 7. Hb. 30 per cent. Bleeding stopped during the day. Blood obtained as usual tested by Dr. Howell showed normal elements of coagulation. The excess of antithrombin had disappeared.

November 12. IIb. 45 per cent. No more bleeding. Widal negative. 
November 19. Hb. 48 per cent. W. B. C. 7,560. Temperature had been normal, but rose to $102.4 \mathrm{~F}$. and remained elevated for ten days (relapse?). Thorax negative. Spleen palpable, but not greatly enlarged.

November 21. Blood culture and Widal negative.

November 24. Hb. 50 per cent. W. B. C. 3,400 .

Dec. 22. Patient discharged in good health. Liver at this time still large and quite firm.

Clinical Diagnosis: Typhoid (?) followed by relapse. Enlarged liver.

This blood-plasma shows the characteristic slow coagulation associated with antithrombin excess. The soft clots may be removed (wiped out with a glass rod) every few minutes and other clots will reform, the process being repeated until the fibrinogen is all used up. This human plasma delayed the coagulation of normal dog plasma, in which we note again the slowly-formed clots and reformation after removal. Spleen extract which is rich in thromboplastin accelerates the coagulation to less than normal, but clots normal plasma in one and one-half minutes. It acts by neutralizing the antithrombin present. Fresh normal dog serum clots human and dog plasma alike in three minutes, indicating that this antithrombin does not retard the action of preformed thrombin on fibrinogen.

It is of interest that within a few days the hemorrhagic tendencies had vanished and blood examination revealed normal elements of coagulation. One is tempted to speculate on this transient upset of the antithrombin-prothrombin balance, and especially its spontaneous return to normal. As no treatment by serum, etc., was given, we are not confused by this factor, and do not hasten to credit this to the treatment. There is no reason to suppose that serum injection would be of value in such cases, as we are dealing not with a lack of any blood element, but with an excess of a normal constituent which is normally held in check by some mechanism not at present clear to us. If the antithrombin is formed by the liver and constantly used up, as some experiments indicate, it is proper to suppose that under certain conditions of liver disease or injury there may be an over-production of this substance. This case had an enlarged liver associated with an obscure infection, but unfortunately we cannot report on the anatomical changes present in the liver.

\section{MILIARY TUBERCULOSIS--EPISTAXIS}

CASE 3.-King. Autopsy No. 375I. Black male, aged 39. Admission June 27, 1912. Death July 12, 1912.

P. H. Patient gave history of syphilis and there was a strong alcoholic history. Patient lost weight from 149 to 100 pounds. Three months prior to admission patient bled profusely from the nose, and had such attacks with considerable frequency. Patient complained of bleeding from nose and swelling of abdomen.

P. E. Indicated probable enlargement of liver and spleen. There was no purpura. Taundice not noted. Skin pricks bleed freely. Bleeding time seven minutes. Red bloo:l-cells 1,900,000. W. B. C. 1.000 . Hb. 26 per cent. Patient 
had profuse epistaxis during the day, perhaps amounting to 200 c.c. This was checked with difficulty.

June 28. Blood aspirated from arm vein directly into oxalate. This blood plasma clotted in a normal manner in four minutes on the addition of calcium. The clot retracted to a small volume and showed no digestion after twenty-four hours. Fibrinogen much below normal (.083 gm. per 100 c.c.-normal $400 \mathrm{gm}$.). This suggested some liver injury.

June 30 . Patient had profuse epistaxis ( 100 c.c. \pm ) which was checked by packing. Hb. 27 per cent. White blood-cells 1,100 .

July 12. Epistaxis and definite bleeding from the gums. Urine constantly negative. Temperature showed an up and down curve from 99 to 102.5 F. Death 5:30 a. m., associated with copious hemorrhage from nasopharynx.

Necropsy. - No. 375l. Anatomical diagnosis: Tabes mesenterica; tuberculous involvement of thoracic duct; general miliary tuberculosis; acute splenic tumor; ascites.

Body is that of an emaciated colored man, $146 \mathrm{~cm}$. long. The pupils are equally dilated. Rigor mortis is marked. There is edema of the ankles and feet. Abdomen is slightly distended, and half way between umbilicus and pubis there is a scar (recent paracentesis). The chest is slightly barrel-shaped. On opening the abdomen it is found to be distended with clear straw-colored fluid, but no fluid is found in the pleural or pericardial cavities. There is great enlargement of the mesenteric lymph-nodes, which vary in size from that of a marble to that of a hen's egg. They are whitish in color, firmly bound to each other and to the vertebral column. The transverse colon and one or two loops of small intestines are also tightly bound to the mass. The whole mass measures roughly $25 \times 15 \mathrm{~cm}$. The heart and lungs are normally placed and no adhesions of the pleura are found.

Heart negative. Lungs show congestion, edema and numerous tubercles.

Spleen weighs $620 \mathrm{gm}$. It is enormously enlarged, and retains its shape very well. The capsule is smooth, glistening and free from adhesions. It is very firm in consistence and of a dark purple color. On section the same color is observel, but it is seen to be thickly studded with great numbers of minute yellowish grains. These are small and almost invisible but are uniformly distributed throughout the whole organ. The trabeculae are not well seen, apparently being widely separated by the increase in the pulp.

Liver weighs $1,500 \mathrm{gm}$., measures $25 \times 19 \times 6 \mathrm{~cm}$. The surface is smooth, free from adhesions, yellowish brown in color and mottled with a few dark reddish areas. On section numerous small, yellowish tubercles are found scattered throughout the whole organ. There is also a slight increase in connective tissue. The lobulation is fairly distinet. Gall-bladder normal.

Microscopical Notes.-Lungs filled with small areas of tuberculosis which are of the exudative type. There is little connective tissue reaction and few giant cells. Edema is well marked.

Spleen is a mass of small tubercles. The reaction is chiefly exudative, the large and small mononuclears being chiefly concerned. Necrosis and degeneration are striking. Kidney and adrenals show tubercles.

In the liver small tubercles with much necrosis are very numerous; the liver cells show much atrophy and fatty degeneration. Other organs are negative.

Blood Examination.-July 12, 8:30 a. m. (three hours after death) blood drawn directly from right heart into oxalate. A few filmy clots had formed, but the fibrinogen analysis showed $110 \mathrm{gm}$. per hundred c.c., which excludes coagulation of any appreciable amount. See previous analysis.

Blood drawn directly into a clean bottle with no oxalate starts to clot within thirty minutes, forming filmy masses on the side of the container. After removal of this filmy clot, secondary clots form slowly. There was some tendency towards digestion of the formed clot after twenty-four hours. Plasma D obtained from normal dog. (Table 6.) 
These observations are incomplete, but indicate pretty conclusively a slight excess of antithrombin in the blood at time of death. This is one of the few cases observed by us in which there was evidence of clot digestion after complete coagulation. We have seen two cases in which this clot digestion or fibrinautolysis was the essential factor in the complex and probably accounted for the prolonged and fatal bleeding. More study of such cases is needed before a report can be made.

Table 6.-Case 3. Coagllation Time of Blood after Deati

\begin{tabular}{|c|c|c|c|c|}
\hline \multirow{2}{*}{$\begin{array}{c}\text { Plasma } H \\
\text { c.c }\end{array}$} & \multirow{2}{*}{$\begin{array}{c}\text { PJasma } D \\
\text { c.c }\end{array}$} & \multirow{2}{*}{ Calcium Drops } & \multicolumn{2}{|c|}{$\begin{array}{l}\text { Coagulation Time } \\
\text { Minutes }\end{array}$} \\
\hline & & & Start & End \\
\hline $\begin{array}{l}1 \\
1 \\
2 \\
\cdots\end{array}$ & $\begin{array}{l}\cdots \\
1 \\
1\end{array}$ & $\begin{array}{r}5 \\
5 \\
14 \\
5\end{array}$ & $\begin{array}{r}12 \\
10 \\
7 \\
5\end{array}$ & $\begin{array}{c}12+ \\
12+ \\
8 \\
6\end{array}$ \\
\hline
\end{tabular}

It is to be remembered that this case did not have outspoken symptoms of hemorrhagic disease, only periodic attacks of profuse epistaxis, and during the last day of life some oozing from the gums. The fibrinogen of the blood was quite low, and this would favor prolonged bleeding from any small wound or abrasion of the mucosa or vessels. A similar condition may be met with in liver cirrhosis with profuse gastric hemorrhage and low fibrinogen content. The blood-clots in such cases are too flabby to seal the ends of the injured vessels.

This case probably belongs in the group of antithrombin bleeders associated with a septicemia. Two weeks before death there was a normal blood coagulation, but later an excess of antithrombin appeared and was a factor in the cozing from the gums and epistaxis. The body was full of small, rapidly-growing miliary tubercles associated with much cell necrosis and tissue destruction. It may be argued that the split products from this dead protoplasm were absorbed, carried to the liver where they caused stimulation and over-production of antithrombin. The liver itself was diseased and filled with tubercles, which process of itself may have actuated this over-production.

\section{GENERALIZED THROMBOSIS - ANTITHROMBIN EXCESS}

CASE 4.-Dean. Autopsy No. 3823. Baby born November 20 after difficult labor necessitating high forceps operation. Chloroform anesthesia thirty-five minutes. Mother recovered well. Placenta examination showed normal tissue. Weight of infant fell continuously from 4,070 to $3,130 \mathrm{gm}$. on the tenth day. Temperature rose to $101.5 \mathrm{~F}$. on the third day, but fell to normal shortly after. On tenth day of life the baby showed retraction of neck, nystagmus and twitching of the extremities. During the next three days these symptoms diminished considerably but the general condition was very poor. 
On the thirteenth day after birth an abscess of left cheek was opened. At this time a discoloration of finger tips of left hand and toes of left foot was noted. This suggested beginning gangrene. Child grew gradually worse and died December 5, 2 a. m. Body placed in ice-box until time of autopsy. Clinical impression: Septicemia; meningitis; gangrene.

December 6, II a. m. Autopsy performed thirty-three hours post-mortem. Blood in heart and large vessels was quite fluid; no clots. This blood clotted readily in contact with the cut tissues. Some of it collected in a test-tube showed no clot at the end of two hours but a firm normal clot at the end of twenty hours.

Necropsy.-Abstract of Protocol 3823.

Anatomical Diagnosis: Multiple thromboses involving umbilical vein, hypogastric arteries and external iliacs, ductus Botalli, aorta and portal vein; aneurysm of ductus Botalli; subdural hemorrhages posterior to cervical cord; slight internal hydrocephalus; pseudo-infarct of liver; fatty degeneration of viscera; atelectrsis; bronchopneumonia.

Body is that of an emaciated, colored baby two weeks old, $50 \mathrm{~cm}$. in length. Rigor mortis is present. 'The stump of the umbilical cord appears normal. There is an abscess on the left cheek from which exudes bloody pus on pressure. The left foot and ankle are of a deep purple color. On section abdomen appears normal. The peritoneal surfaces are smooth and glistening. The mesenteric lymph-glands are injected and seem slightly enlarged and in places hemorrhagic. Thymus is normal. The pericardial sac contains a normal amount of fluid. The surface is smooth and glistening. The lung surface shows many deeply injected areas varying from $I$ to $2 \mathrm{~cm}$. in diameter. On section they are air-containing for the most part, but a few reddish, slightly elevated areas are to be found.

The spleen is rather soft and grayish in color. The Malpighian corpuscles can be seen as minute grayish dots. Stomach and duodenum are normal. The bile ducts are patent.

Liver: On the anterior surface of the left and the middle portion of the right lobe is an irregularly outlined area measuring $41 / 2 \times 5 \mathrm{~cm}$. which is deep purple in color. On section the purple area above described is definitely outlined and contrasts sharply with the adjacent tissue. It is of a reddish purple color with indistinct lobulation. The parenchyma elsewhere has a yellowish, opaque cast. The portal vein at the hilus and extending into the substance of the liver is occluded by a thrombus.

The intestines are injected. On opening the aortia a thrombus is found beginning $1 \mathrm{~cm}$. above the bifurcation and extending down into both iliacs, on the left to the opening of the epigastric artery; on the right about $1 \mathrm{~cm}$. below the opening of the right hypogastric artery.

The brain is found to be edematous and the ressels injected, and an excess of fluid flowed from the ventricles. The pia is otherwise normal. On section the lateral ventricles are somewhat dilated. On the posterior surface of the cervical cord is found a clot which covered an area $3 \mathrm{~cm}$. in length. The clot appears recent. Other organs need not be described.

Microscopical Notes.-The vessels in some instances show thrombi which are partly organized. Lungs show some interstitial pneumonia somewhat like that seen in congenital syphilis. The alveoli contain an albuminous exudate and many alveolar cells but no fibrin. Some sections show extreme atelectasis. The capillaries of the liver are free from blood islands and there is no evidence of syplilis. Each lobule shows a central fatty degeneration involving about half the parenchyma. Pancreas and other viscera are normal. There is no evidence of syphilis.

This case, although incomplete, evidently presented an excess of antithrombin in the blook at time death. There may have been a low prothrombin fraction, but the great accejeration of coagulation of the 
blood in contact with the cut tissues speaks against this. We may assume with some certainty that this case showed an upset of the antithrombin-prothrombin balance, and this is of interest chiefly because of its association with extensive vascular thrombosis. This infant probably was suffering from a general infection and the antithrombin excess may be classed with that found in severe septicemia and reported previously (Whipple ${ }^{1}$ ).

In this instance we believe the excess of antithrombin is in part deperident on extensive thrombus formation. Under such conditions the production of thrombin must be considerable, and its escape into the blood-stream inevitable. The introduction of thrombin into the bloodstream causes a transient rise of antithrombin as can be studied in the $\operatorname{dog}\left(\right.$ Howell $\left.{ }^{4}\right)$. When a thrombus is developing slowly in the bloodstream we may assume a steady escape of thrombin and more or less elevation of the antithrombin curve. It may not be far from the truth to think of this antithrombin wave as a process tending to delimit the growth of any thrombus. We may consider this antithrombin reaction under these conditions as protective and tending to stop thrombus development. It will be of interest to follow this antithrombin curve in patients where there is some certainty of a progressive thrombosis or even an endocarditis of the malignant type. It is more than likely that there may appear periods of low antithrombin blood content which would faror the start or growth of a thrombus.

\section{ALLASTIC ANEMIA, PURPURA, BLEEDING, ANTITHROMBIN}

Case 5.-Rykowski. Autopsy No. 3724. White male, aged 16. Admission April 3, 1912. Death May 6. Patient complained of faintness.

Present illness began nine weeks before death with epistaxis and bleeding of gums. Definite yellow color in skin noted one week before this.

April 3. Red blood-cells 796,000, white blood-cells 2,200, Hb. 15 per cent. Differential count showed small mononuclear leukocytes 83 per cent. Polymorphonuclear leukocytes 14 per cent. Myelocytes $21 / 2$ per cent. Blood clotted in five minutes, but the bleeding time was over twenty minutes. Examination of the eyes showed a definite retinitis with extensive hemorrhage. Sclerae pale and white.

April 10. Strongyloides stcrcoralis found in considerable number in stools. Wassermann negative.

April 16. Bleeding time very much prolonged and gums ooze blood constantly. Hemoglobin has fallen to 10 per cent.

April 17 patient was given an indirect transfusion of 500 c.c. defibrinated blood obtained from brother. Shortly after it his temperature rose to $105.6 \mathrm{~F}$. accompanied by a chill.

April 18. Purpura noted in skin and mucous membranes of tongue. Epistaxis started and continued in spite of epinephrin.

April 19. Epistaxis with slow oozing continued. Blood culture and Widal both negative. Hb. 22 per cent. Red blood-cells 1,224,000. W. B. C. 1,280. A few blood platelets were noted.

4. Personal communication. 
April 21. Hb. 17 per cent.

April $2 \bar{\tau}$, Hb. 12 per cent. Bleeding continued.

May 3, Hb. 9 per cent. Epistaxis and oozing continued.

May 5, respirations slow and deep. Fresh patches of purpura noted. Urine free from bile, urobilin and albumin. 'lemperature continued uniformly between 99 and $100.1 \mathrm{H}$. during the previous few days.

May 6, 12:05 p. m., death. Blood aspirated from heart directly into oxalate at $1: 30$ p. $\mathrm{m}$.

Anatomical Diagnosis.-Hemorrhage in the subeutaneous tissues, pericardium, submucous tissues of the trachea, stomach, intestine and lungs; pericardial effusion; marked anemia; fatty degeneration of heart muscle; tuberculous bronchial lymphadenitis; chronic pleural adhesions; rectal polyps; adenoma of liver; bronchopneumonia with necrosis; central liver necrosis.

Necropsy.-Body is that of a very well nourished, white boy, $152 \mathrm{~cm}$. long. The skin is waxy in appearance. The mucous membranes are extremely pale. There are a few small, purpuric spots over the right side of the forehead and elsewhere over the face. There is an excoriation on the left side of the nose and one on the upper lip. A few small ecchymoses over the arm and fading ones elsewhere on the body. These are not conspicuous below the waist except for a rather large conglomerate area on the right leg. Rigor mortis is well marked. The abdominal viscera are normally disposed and serous surface normal. The liver and the rest of the organs are extremely pale. The mesenteric lymph-nodes are large and firm. Sections, yellowish-gray in color, homogeneous in consistence. The thymus is fairly prominent and extends down over the upper part of the pericardium. It contains a great deal of fat. The pericardial surfaces both parietal and visceral are covereed with hemorrhages of various sizes from that of a pin-head up to several millimeters in diameter, flame shaped or streaked.

Liver measures $24 \times 15 \times 7 \mathrm{~cm}$, weighs 1,200 gm. Gall-bladder contains thick, viscid, black bile. The edge is fairly rounded. The color is pale. On section the lobulation is indistinct but regular.

Bone-marrow is firm and yellowish in color, made up almost entirely of fat. There are only a few red specks representing clumps of bone-marrow cells.

Iricroscopical Sections.-Lungs: Areas of bronchopneumonia in which colonies of bacteria are conspicuous. There is much cell necrosis in these areas and fibrin threads are very numerous. Fvidently the cell necrosis freed sufficient thromboplastin to neutralize the excess of antithrombin in the blood. One of the large vessels in an area of necrosis contains a small clot in which the fibrin is confined to the margin of the vessel.

Spleen: Malpighian bodies normal. Pulp contains little blood and the venules show slight thickening of their walls. No pigment. Lymph-nodes are negative.

Bone-marrow made up of fat cells. There are two or three clumps of normal marrow cells numbering six to twelve-complete aplasia.

Duodenum shows evidence of old hemorrhage into the villi, where are found mumerous phagocytes containing yellow granular pigment.

Liver: The cells show slight increase in the fine, yellow, intracellular pigment. There is a central necrosis involving perhaps one-tenth of the parenchyma, associated obviously with the necrotizing bronchopneumonia. Other organs normal.

Blood Examination.-May 6, 12:05 p. m., death. Blood drawn from heart into oxalate at $1: 30 \mathrm{p} . \mathrm{m}$. Blood drawn into a clean bottle (no oxalate) started to elot in forty-five minutes, filmy clots forming on the side of the container. After wiping out with a glass rod more clots formed in one hour. Incomplete coagulation in six hours. After twenty hours the clot was tough and firm, no more forming after this. 
Some of this blood (not oxalated) was centrifugalized and this procedure and subsequent handling was associated with acceleration of clotting. The anemia was profound and 50 c.c. of blood after centrifugalization yielded only about 1 c.c. of red cells.

Table 7.-Case 5. Coaglilation lime of Blood after Death

\begin{tabular}{|c|c|c|c|c|}
\hline \multirow{2}{*}{$\begin{array}{c}\text { Plasma } \\
\text { c.c }\end{array}$} & \multirow{2}{*}{$\begin{array}{c}\text { Plasma D } \\
\text { c.c }\end{array}$} & \multirow{2}{*}{ Calcium Drops } & \multicolumn{2}{|c|}{$\begin{array}{c}\text { Coagulation Time } \\
\text { Minutes }\end{array}$} \\
\hline & & & Start & End \\
\hline $\begin{array}{l}\ddot{1} \\
1 \\
2 \\
3\end{array}$ & $\begin{array}{c}1 \\
\cdots \\
1 \\
1 \\
1\end{array}$ & $\begin{array}{r}5 \\
5 \\
10 \\
15 \\
20\end{array}$ & $\begin{array}{r}-15 \\
9 \\
14 \\
11\end{array}$ & $\begin{array}{r}5 \\
17 \\
- \\
-\end{array}$ \\
\hline
\end{tabular}

Plasma D was from a normal dog. The coagulation of all mixtures of plasma $H$ was in a fractional manner as described for the whole blood, although very much less marked. (Table 7.) After twenty-four hours the same plasmas were tested with some fresh spleen extract.

TABjes 8.-Case 5. Coagclatiox Time with Spleex Extract

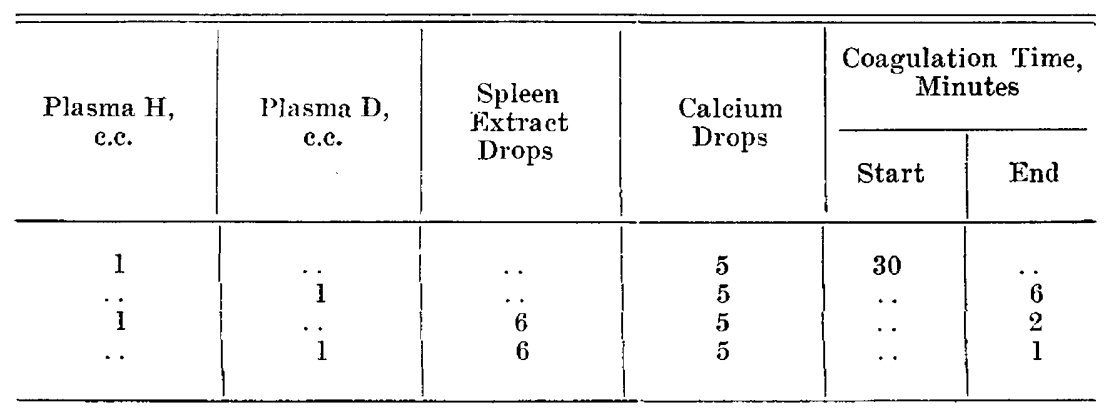

Tables 7 and 8 and the observation on the whole blood give conclusive evidence of an excess of antithrombin. There is no lack of prothrombin, as the spleen extract clots the human plasma at once, due simply to a neutralization of the antithrombin, which is the only abnormal factor in the equation.

It is of interest to note the effect of an indirect transfusion which was followed by a febrile reaction and doubled the patient's hemoglobin. The bleeding continued and evidently the antithrombin excess was in no great degree influenced by this procedure. On theoretical grounds it does not seem justifiable to introduce defibrinated blood which is rich in thrombin into a circulation in which antithrombin is in excess. There is erery reason to suppose this procedure would be followed by an antithrombin wave which might make matters even worse. The transfusion if attempted shonld be direct. 


\section{LEUKEMA, PURPURA, BLEEDING, ANTITHROMBIN}

CASE 6.-Shema. Medical No. 31151. White male, aged 26. Admission July 7. Patient was in a desperate condition due to repeated hemorrhage. Patient lad suffered from severe hemorrhages from the nose during the past three weeks. The nasal passages had been packed but the bleeding was not completely checked. Gums had been oozing constantly up till the last day of life. Patient was dysp neic and very weak. There was no history of any previous attacks of hemorrhage, and family history was normal. Patient's past history was negative except for an attack of gonorrhea about five years previously, associated with some joint complications.

Examination.-The patient is very pale and thin. Respirations were of air hunger type. Purpura everywhere over trunk and Iimbs. The patches were of all sizes from pin-head specks up to spots $1 \mathrm{~cm}$. in diameter, both old and recent. There was edema of feet and ankles. No icterus. The spleen was enlarged. Red blood-cells $1,092,000$. W. B, C. 75,300. Hb. less than 10 per cent. Blood smears examined by Dr. Guthrie gave evidence favoring the diagnosis of chronic myelogenous leukemia. There were numerous immature polymorphonuclear leukocytes and myelocytes. Eosinophils were numerous. Nucleated reds very abundant.

Death occurred at $12 \mathrm{~m}$. July 7 . No autopsy. Blood aspirated from heart directly into oxalate at 3:30 p. m. Blood also drawn directly into a clean bottle with no oxalate and centrifugalized. During this process a flabby clot formed at $3: 50 \mathrm{p} . \mathrm{m}$. This small clot was removed and other secondary clots reformed and were removed at intervals during the next two hours. Small clots formed in this same plasma over night, completing the coagulation, and no subsequent elots reformed after this time. There was no autolysis of the blood clot.

Plasma and serum $C$ from a normal cat. Spleen extract (dilute) from same eat sacrificed at time of experiment. (Table 9.)

table 9.-Case 6. Coagulation time of Blood after Deati

\begin{tabular}{|c|c|c|c|c|c|c|}
\hline \multirow{2}{*}{$\begin{array}{c}\text { Plasma } H \text {, } \\
\text { c.c. }\end{array}$} & \multirow{2}{*}{$\begin{array}{l}\text { Plasma (', } \\
\text { c.c. }\end{array}$} & \multirow{2}{*}{$\begin{array}{l}\text { Serum C, } \\
\text { c.c. }\end{array}$} & \multirow{2}{*}{$\begin{array}{l}\text { Spleen } \\
\text { Extract } \\
\text { Drops }\end{array}$} & \multirow{2}{*}{$\begin{array}{l}\text { Calcium } \\
\text { Drops }\end{array}$} & \multicolumn{2}{|c|}{$\begin{array}{c}\text { Coagulation Time, } \\
\text { Minutes }\end{array}$} \\
\hline & & & & & Start & End \\
\hline 1 & & $\ldots \ldots$ & & 3 & 17 & $* 25-60+$ \\
\hline . & 1 & & & 2 & 4 & 5 \\
\hline 1 & 1 & $\ldots \ldots$ & $\ldots \ldots$ & 5 & $41 / 2$ & 7 \\
\hline 2 & 1 & $\ldots \ldots$ & $\ldots \ldots$ & 7 & $6^{-}$ & ${ }^{*} 8+$ \\
\hline 3 & 1 & $\ldots \ldots$ & $\ldots \ldots$ & 9 & 7 & $\approx 10+$ \\
\hline 1 & $\ldots \ldots$ & 1 & $\ldots \ldots$ & 2 & 3 & 10 \\
\hline 1 & $\ldots \ldots$ & $\ldots \ldots$ & 15 & 2 & . & 3 \\
\hline 1 & $\ldots \ldots$ & $\ldots \ldots$ & 5 & 2 & $\ldots \ldots$ & 11 \\
\hline$\ldots$ & 1 & $\ldots \ldots$ & & 2 & $\ldots \ldots$ & 4 \\
\hline & 1 & & 5 & 2 & $\ldots \ldots$ & $11 / 2$ \\
\hline$\ldots$ & 1 & 1 & $\ldots \ldots$ & 2 & $\ldots \ldots$ & $1 \overline{1 / 2}$ \\
\hline$\ldots \ldots$ & 1 & $\cdots \cdots$ & 15 & 2 & $\ldots \ldots$ & $3 / 4$ \\
\hline
\end{tabular}

* Coagulation proceeded slowly in fractions after clots were wiped out by glass rod at intervals.

Table 9 shows clearly that the human blood contained an excess of antithrombin and otherwise was normal. The cat serum contained a good deal of thromboplastin and accelerated coagulation of normal as well as human plasma. The human plasma caused definite delay in 
coagulation of normal cat's plasma. The fibrinogen was low, but not under $0.1 \mathrm{gm}$. per 100 c.c.

The two preceding cases furnish evidence that the purpuras and various hemorrhagic symptoms often associated with blood diseases, especially leukemia, are due to an excess of antithrombin. The case of aplastic anemia with inactive bone marrow almost completely excludes the bone marrow as a factor in this antithrombin upset.

It is unfortunate that the platelets were not enumerated in these two cases. It is possible that they were diminished in the first case of aplastic anemia, but very unlikely in the second case (Shema) of chronic leukemia. The platelets are usually increased in number in myelogenous leukemia.

Duke" has recently called attention to certain cases of purpura and bleeding in which the platelets are greatly diminished. He believes this to be the sole cause of the tendency to hemorrhage, but it does not seem that this point has been established beyond reasonable doubt, as he has not followed the elements of blood coagulation. The bleeding time in chloroform poisoning may be hours and the coagulation time normal. The platelets are normal or increased, and the essential lesion is a great drop in fibrinogen, rendering the clots too flabby to check hemorrhage.

In the cases reported by him, it is possible that an excess of antithrombin was present. Blood drawn through the tissues (ear puncture) is of no value for the determination of antithrombin (when negative) as the tissue juices may have neutralized all the excess of antithrombin. There may be a sufficient excess of antithrombin to overcome the thromboplastin of the tissues and favor prolonged oozing from cuts and punctures (delayed bleeding time). One can imagine an excess of antithrombin capable of delaying the coagulation of the blood on contact with injured tissues (ear puncture) and so favoring bleeding, yet this excess might be used up by this very contact with the cut tissues, and the blood escaping give a coagulation time of seven to eight minutes. Duke's suggestion that the platelet thrombi normally forming at the ends of the cut vessels are a great aid in stopping hemorrhage is perfectly logical and probably true. There may well be other factors concerned in the diseases which he has studied, and these should be controlled, as the platelet theory is more or less a mechanical explanation.

It is conceivable that the thromboplastic content of various tissues may vary widely under different conditions and may be concerned in promoting or checking hemorrhage when the normal factors of blood coagulation are upset. It is not difficult to imagine a drop in thromboplastin tissue content when there has been a long period of antithrombin excess in the blood, and it is possible that this may be an important

5. Duke, W. W.: The Archives Int. Med., 1912, $x, 445$. 
factor. The methods available at present give unsatisfactory results in attempting estimates of the thromboplastin content of various organs and tissues.

There is a tendency among certain writers to attribute the symptoms of hemorrhagic disease, purpura, bleeding from the mucous membranes, etc., to a temporary increase in fragility or permeability of the capillary vessels. This seems to us to be merely avoiding the issue and ignoring well established facts, which alone are sufficient to explain all the symptoms. It will be admitted that bleeding from the gums, mucous membranes, skin punctures, etc., can be produced experimentally in a variety of ways. We may produce it experimentally by chloroform poisoning, which acts by decreasing the fibrinogen almost to zero in extreme cases, and by peptone injections under favorable conditions where an excess of antithrombin is the essential feature. The bleeding will appear within a few hours after this abnormal condition of the blood appears and vanish as the blood returns toward its normal equilibrium. Surely it is asking much of one's imagination to postulate a variation in fragility of the vessel walls during this short space of time. It will be noted, too, that the bleeding occurs around the teeth where there is a constant inflammation and tissue injury due to trauma and bacteria. The mucous membranes are delicate and subjected to constant trauma which we must imagine cause trivial injuries to the surface and capillaries which are so close to the surface. It will be recalled that purpura is always most marked on surfaces exposed to trauma. It is not too much to suppose that trifling capillary injury is being constantly repaired under normal conditions. Given an abnormality of coagulation, even the most trivial injury may permit of escape of blood into the tissues, or from the surface of the mucous membranes.

\section{MELENA NEONATORUM-PROTHROMBIN ABSENT}

Case 7.-Baby Chapman, age 2 weeks. Birth May 26, 1912. Death June 10, 2 a. $\mathrm{m}$.

Clinical History.-Mother, aged 25, has had two children and one miscarriage. The last child born about a year ago is healthy. Mother gave a positive Wassermann reaction.

May 26. Spontaneous delivery with no difficulty. Placenta normal; no evidence of syphilis. Child measured $47 \mathrm{~cm}$, and weighed $2,800 \mathrm{gm}$. at birth. The weight of the child diminished as usual and then remained constant with no upward tendeney. During the last week weight fluctuated between 2,500 and $2,450 \mathrm{gm}$. Temperature was normal.

June 4. Retraction of foreskin, which was associated with a good deal of bleeding.

June 5. Continuous oozing from foreskin in spite of all efforts to check bleeding.

June 6. Hemorrhage continued in spite of clamps, various styptics and actual cautery. Human serum, 3 c.c., given subcutaneously. Icterus of the conjunctivae noted.

June 7. No bleeding. Condition much better, given calcium lactate. 
June 8. Human serum, 2.5 c.c., given subcutaneously; slight bleeding noted from the cord and little blood in vomitus. No blood in stools.

June 9,9 p. m. Considerable hemorrhage from the umbilicus, followed by great loss of strength and death June 10 at 2 a. $\mathrm{m}$.

Clinical Diagnosis.-Hemorrhagic disease of new-born; syphilis.

Autopsy June 10, 10 a. m. No. 3735 .

Anatomical Diagnosis.-Hemorrhagic disease; absence of blood clots in vascular system; general icterus; subcutaneous and pulmonary hemorrhages; acute splenic tumor; anemia; bronchopneumonia; absence of prothrombin.

Body is that of a well-developed normal appearing negro male infant, $47 \mathrm{~cm}$. in length. The body is cool and rigor mortis is present. Jaundice is wall marked in the mucous memibranes, conjunctivae and subcutaneous tissues. Thorax opened and blood aspirated from the heart in situ; about 30 c.c. of blood obtained. The blood is quite fluid, and there is no evidence of any clot formation in any part of the vascular system. Thorax normai, except for some small areas of purpura in the subcutaneous tissue over the thorax. There are ecchymoses in the thymus and indefinite purplish splotches in the lungs. Thymus is of normal size, very pale, lemon-yellow color and trans?ucent, normal on section.

Heart is of normal size, firmly contracted. The intima and valves throughout are quite normal. Heart muscle is of a pale brownish red color and uniform on section.

Lungs are voluminous and paie lemon color, downy feeling anteriorly, rather heavy and moist posteriorly. The bronchi contain slimy mucus and some vomitus. The rucosa is pale everywhere. The vessels at the hilum are normal and contain no clots. Section shows pale, uniform upper and anterior portion, while the posterior portions show a mottled appearance due to indefinite splotches and specks of bright purple color, looking more like tiny areas of hemorrhage than like areas of consolidation.

Spleen weighs about $6 \mathrm{gm}$. It is about double the size of the normal spleen of an infant of this size. It is soft; the edges are rounded. The capsule is thin and delicate. Section shows a rather velvety and deep purplish pulp having a chocolate tinge. The Malpighian bodies are small and cleanly outlined. The pulp scrapes off easily and obscures the trabeculae.

Liver is normal size and definitely jaundiced, having an olive-green color with a slight yellowish tint. The lobulation is regular. The cut section is uniform and rather translucent. The gall-bladder contains thin fluid bile and is not particularly distended. No obstruction to the outflow of bile ean be made out. Pancreas is of normal size, very pale, milky-white and uniform in appearance.

Mesenteric glands are definitely enlarged and rather conspicuous in the mesentery where the fat has undergone some regression. The lymph-nodes in other parts of the body are rather conspicuous but uniformly pale and translucent on section.

Stomach contains curds and milky fluid. The mucosa is pale. There is no evidence of any hemorrhage. The mucous membrane is intact throughout the intestinal tract wherever examined. The small and large intestine show no evidence of any blood escaping from the mucosa. Intestines are decidedly pale, and except for a certain amount of distention with gas, perfectly normal in gross. Adrenals are rather smaller than normal, about one-half the size of a normal child, but uniform in appearance, with a regular cortex and medulla.

Kidneys are normal. Bladder and prostate are normal. Aorta is perfectly elastic and normal throughout.

Bones: The line of ossification at the lower end of the femur is slightly wider than normal but straight, regular and sharply outlined. The bone-marrow has a currant red and juicy appearance. Brain could not be examined.

Microscopical Notes.- Thymus is normal, not of regressive type. Mononuclear eosinophils are numerous. 
Lungs show lesions suggestive of congenital syphilis. The septa are thick and the stroma rich in mononuclear cells. In places are patches of desquamative pneumonia; no fibrin is found in any section. The blood-vessels show thickened walls and the capillaries are relatively inconspicuous in the walls of the alveoli.

Spleen shows normal Malpighian corpuscles. The pulp is full of blood and the sinuses engorged. Phagocytosis by endothelial cells is rare. Nucleated red cells are numerous. Few eosinophils. Mesenteric glands are uniform. Sinuses dilated with endothelial cells, many of which are actively phagocytic, some including as many as six mononuclear cells. Kidney, adrenal and prostate are normal.

The liver cells are normal except for conspicuous bile canaliculi filled with greenish colloid. Between the columns of liver cells are a few nests of mononuclear cells like those seen in congenital syphilis. Levaditi stains in all organs show no spirochetes.

Blood Examination.-Blood taken from right auricle at 10:30 a. m. There were no clots to be found anywhere in the vascular system after the most careful search.

1. Blood containing no oxalate (about 10 c.c.) taken from heart. The corpuseles settled by gravity giving material used in Table 10 (Plasma H, nonoxalated). There was no clotting after a period of forty-eight hours.

2. Blood 20 c.c. added to 2 c.c. sodium oxalate ( 1 per cent.) and centrifugalized, giving a slightly turbid orange-yellow plasma whose froth was definitely greenish from the presence of bile pigments. The calcium oxalate precipitate was more abundant than usual after centrifugalization. Plasma $\mathbf{H}$ - oxalated -used.

3. Spleen Extract $H$, made by grinding the spleen pulp with sand and two volumes of Ringer's solution followed by filtration.

4. Spleen extract $D$, fresh extract of same type from dog.

5. Plasma D, and 6, Serum D, both fresh plasma and serum from normal dog.

Table 10.-Case 7.-Coagclation Time of Blood after Death

\begin{tabular}{|c|c|c|c|c|c|}
\hline $\begin{array}{c}\text { Plasma H, } \\
\text { Oxalate, } \\
\text { c.c. }\end{array}$ & $\begin{array}{c}\text { Plasma } \mathrm{H}, \\
\text { No Ox. } \\
\text { c.c. }\end{array}$ & $\begin{array}{c}\text { Plasma D, } \\
\text { c.e. }\end{array}$ & $\begin{array}{l}\text { Serum D } \\
\text { c.c. }\end{array}$ & $\begin{array}{c}\text { Calcium } \\
\text { Drops }\end{array}$ & $\begin{array}{c}\text { Coagulation Time } \\
\text { Minutes }\end{array}$ \\
\hline $\begin{array}{c}\ldots \\
\ldots \\
\cdots \\
1 \\
1 \\
2 \\
2 \\
\ldots\end{array}$ & $\begin{array}{c}1 \\
\text { I } \\
\ldots \\
\ldots \\
\ldots \\
\ldots \\
\ldots \\
\ldots\end{array}$ & $\begin{array}{l}\cdots \\
\ddot{1} \\
\ddot{1} \\
1 \\
1 \\
1\end{array}$ & $\begin{array}{c}1 \\
2 \\
\ldots \\
\ldots \\
\ldots \\
\ldots \\
\because \\
\end{array}$ & $\begin{array}{r}\cdots \\
\because \\
5 \\
5 \\
7 \\
12 \\
12 \\
10\end{array}$ & $\begin{array}{l}9 \\
9 \\
7 \\
* \\
3 \\
4 \\
4 \\
5\end{array}$ \\
\hline
\end{tabular}

$*$ No clot in forty-eight hours. $\dagger=1$ c.c. Ringer's solution.

1. Dog plasma (1 c.c.) + spleen extract $H, 7$ drops + calcium, 5 drops $=$ clot in $11 / 2$ minutes.

2. Plasma H., no oxalate ( 1 c.c.) + spleen extract $H, 9$ drops $=$ no clot in 24 hours; at this time clotted by adding serum D.

3. Plasma H., oxalated ( 1 c.c.) + spleen extract D, 5 drops $=$ no clot in 24 hours; then clotted by serum $D$.

4. Plasma H., oxalated ( 1 c.c.) + spleen extract D, 4 drops $=$ no clot in 24 hours; then clotted by serum $D$. 
5. Plasma H., oxalated ( 1 c.c.) + serum D ( 1 c.c.) $=$ clot formed in 12 minutes.

6. Plasma H., oxalated ( 1 c.c.) + pure thrombin, 7 drops $=$ clot; starts in 6 minutes; complete in 10 minutes.

7. Plasma H., no oxalate ( $1 / 2$ c.c.) + pure thrombin, 7 drops $=$ firm clot in 13 minutes.

The data above make it absolutely certain that in this case of melena neonatorum the only abnormality was the absence of prothrombin. The plasma is readily clotted by fresh serum or pure thrombin which later was obtained through the kindness of Dr. Howell and prepared after his method described in a recent publication. This plasma does not delay the coagulation of normal plasma showing an absence of any antithrombin excess. Fibrinogen and calcium are present at least in normal amounts. The spleen extrast from this case contains an abundance of thromboplastin. There is clinical evidence of improvement following treatment by human serum which, of course, furnishes the missing factor of coagulation, but in this case the improvement was transient.

We have reported a similar case in an earlier communication, in which the evidence pointed pretty conclusively to a total absence of prothrombin. This case strengthens the argument that this group of cases is quite clean eut with constant blood-findings. There was conclusive proof of fibrin formation in the lung of this case previously reported, but this coagulum had been formed several days previous to the onset of hemorrhagic tendencies and death. Also this first case gave no evidence of any organic or infectious disease and no hint of the source of prothrombin formation.

The case reported here shows evidence of the syphilitic virus although no spirochetes can be demonstrated and the placenta was normal. It is possible that syphilis was important in the etiology of this case, but study of the organs gives no clue to the origin of prothrombin.

\section{CONCLUSIONS}

The antithrombin-prothrombin balance in the blood is in delicate equilibrium but under normal conditions there are strong factors which can preserve this balance. Under experimental conditions this may necessitate rapid neutralization of antithrombin excess; again a rapid production of fresh antithrombin or prothrombin. There are wide margins of safety in the normal animal.

This antithrombin-prothrombin balance may be temporarily or permanently upset under disease conditions as reported in the preceding cases. The prothrombin factor is rarely involved, but it may drop to zero (Case 7) or to a low level (Case 1) which will be associated with hemorrhagic symptoms. 
The antithrombin factor is frequently inrolved and if this element is much increased above normal there will be a tendency toward hemorrhage, purpura, etc., depending in part on the duration of the change, but especially on the amount of antithrombin excess.

It may be assumed that during these wide fluctuations of antithrombin it may fall below normal, whereupon there would be a tendency to vascular thrombosis. Given a low antithrombin content a minor injury to the intima might initiate a thrombus which would grow rapidly. With the growth of a thrombus there would be the formation of much thrombin which would escape into the blood and stimulate the organ (liver) prolucing antithrombin. This might result in an antithrombin wave-a period of antithrombin excess (Case 4)-which would check the growth of thrombi and give the endothelium opportunity to cover over the fresh thrombi, thus removing the foci of thrombin formation. The antithrombin wave may fall promptly to normal or persist for weeks, but if its duration is a matter of days there will appear signs of hemorrhagic disease (Case 2).

It seems highly probable that under certain conditions liver injury or disease may be associated with an excess of antithrombin in the blood capable of giving hemorrhagic symptoms (Cases 1 and 2). Also certain substances in the blood (peotone, thrombin) will bring about an overproduction of antithrombin due probably in great part to stimulation of the liver. Under this heading may be grouped cases of septicemia (reported previously), pneumonia (Dochez) endocarditis, miliary tuberculosis (Case 3) generalized vascular thrombosis (Case 4), etc.

True hemorrhagic disease is rarely associated with simple obstructive icterus, contrary to common belief. Delayed coagulation time in jaundice may be influenced favorably by calcium, but such.cases do not suffer from bleeding unless there is some other abnormality-for example, an excess of antithrombin. In these rare cases of true hemorrhagic disease associated with profound icterus, we may presuppose some liver disease and an upset in the antithrombin-prothrombin balance (Case 1). Calcium has no effect on this condition.

Disease of the blood-forming organs may present symptoms of hemorrhagic disease (aplastic anemia, Case 5 and leukemia, Case 6) because of an excess of antithrombin in the blood. It is unlikely that the bloodforming tissues are directly concerned in the antithrombin production as this element is much in excess in the case of anemia (Case 5) with complete marrow aplasia. It is possible that the products of blood-cell disintegration may stimulate an overproduction of antithrombin. It will be recalled that purpura and hemorrhagic tendencies are more common in acute leukemias in which the evidences of blood-cell disintegration are most marked. It is probable that the majority of hemorrhagic 
cases and purpuras associated with leukemias and anemias belong in the antithrombin group.

The disease called melena neonatorum in many, perhaps all, instances is characterized by a relatively sudden disappearance of prothrombin from the blood. This condition usually develops during the first two weeks of life and is often fatal. The cases react favorably to fresh serum treatment.

Treatment of hemorrhagic disease should follow a careful analysis of the blood as harm can be done by faulty treatment. In cases of low or absent prothrombin, it is clear that serum which is rich in this element is indicated and in many cases produces almost miraculous cures. It should be given intravenously if possible. Direct transfusion is of even greater value.

Treatment of antithrombin cases offers great difficulties. Serum treatment offers no help and it may even stimulate a still greater overproduction of antithrombin. Indirect transfusion is open to the same criticism (Case 5) as large amounts of thrombin are introduced. It may be possible to find some safe way to introduce thromboplastin into the blood-stream in the hopes of neutralizing the antithrombin excess. If the means by which the antithrombin is neutralized or used up in the normal body can be found out by various animal experiments, the solution of this problem in treatment of antithrombin cases may be reached. At present direct transfusion seems to offer the greatest hope of permanent benefit. 